\title{
Research Article \\ Coupled Fixed-Point Theorems for Contractions in Partially Ordered Metric Spaces and Applications
}

\author{
M. Eshaghi Gordji, ${ }^{1}$ Y. J. Cho, ${ }^{2}$ S. Ghods, ${ }^{3}$ \\ M. Ghods, ${ }^{4}$ and M. Hadian Dehkordi ${ }^{4}$ \\ ${ }^{1}$ Department of Mathematics, Semnan University, P.O. Box 35195-363, Semnan, Iran \\ ${ }^{2}$ Department of Mathematics Education and the RINS, Gyeongsang National University, \\ Chinju 660-701, Republic of Korea \\ ${ }^{3}$ Department of Mathematics, Islamic Azad University, Semnan Branch, Semnan, Iran \\ ${ }^{4}$ Department of Mathematics, Iran University of Science and Technology, Narmak, Tehran, Iran \\ Correspondence should be addressed to M. Eshaghi Gordji, madjid.eshaghi@gmail.com and Y. J. \\ Cho, yjcho@gnu.ac.kr
}

Received 30 September 2011; Revised 20 December 2011; Accepted 24 December 2011

Academic Editor: Stefano Lenci

Copyright (c) 2012 M. Eshaghi Gordji et al. This is an open access article distributed under the Creative Commons Attribution License, which permits unrestricted use, distribution, and reproduction in any medium, provided the original work is properly cited.

Bhaskar and Lakshmikantham (2006) showed the existence of coupled coincidence points of a mapping $F$ from $X \times X$ into $X$ and a mapping $g$ from $X$ into $X$ with some applications. The aim of this paper is to extend the results of Bhaskar and Lakshmikantham and improve the recent fixedpoint theorems due to Bessem Samet (2010). Indeed, we introduce the definition of generalized $g$ Meir-Keeler type contractions and prove some coupled fixed point theorems under a generalized $g$-Meir-Keeler-contractive condition. Also, some applications of the main results in this paper are given.

\section{Introduction}

The Banach contraction principle [1] is a classical and powerful tool in nonlinear analysis and has been generalized by many authors (see [2-15] and others).

Recently, Bhaskar and Lakshmikantham [16] introduced the notion of a coupled fixedpoint of the given two variables mapping. More precisely, let $X$ be a nonempty set and $F$ : $X \times X \rightarrow X$ be a given mapping. An element $(x, y) \in X \times X$ is called a coupled fixed-point of the mapping $F$ if

$$
F(x, y)=x, \quad F(y, x)=y \text {. }
$$


They also showed the uniqueness of a coupled fixed-point of the mapping $F$ and applied their theorems to the problems of the existence and uniqueness of a solution for a periodic boundary value problem.

Theorem 1.1 (see Zeidler [15]). Let $(X, \leq)$ be a partially ordered set and suppose that there is a metric $d$ on $X$ such that $(X, d)$ is a complete metric space. Let $F: X \times X \rightarrow X$ be a continuous mapping having the mixed monotone property on $X$. Assume that there exists $k \in[0,1)$ such that

$$
d(F(x, y), F(u, v)) \leq \frac{k}{2}[d(x, u)+d(y, v)]
$$

for all $x \geq u$ and $y \leq v$. Moreover, if there exist $x_{0}, y_{0} \in X$ such that

$$
x_{0} \leq F\left(x_{0}, y_{0}\right), \quad y_{0} \geq F\left(y_{0}, x_{0}\right),
$$

then there exist $x, y \in X$ such that $x=F(x, y)$ and $y=F(y, x)$.

Later, in [17], Lakshmikantham and Ćirić investigated some more coupled fixed-point theorems in partially ordered sets, and some others obtained many results on coupled fixedpoint theorems in cone metric spaces, intuitionistic fuzzy normed spaces, ordered cone metric spaces and topological spaces (see, e.g., [18-25]). follows.

In [9], Meir and Keeler generalized the well-known Banach fixed-point theorem [1] as

Theorem 1.2 (Meir and Keeler [9]). Let $(X, d)$ be a complete metric space and $T: X \rightarrow X$ be a given mapping. Suppose that, for any $\epsilon>0$, there exists $\delta(\epsilon)>0$ such that

$$
\epsilon \leq d(x, y)<\epsilon+\delta(\epsilon) \Longrightarrow d(T(x), T(y))<\epsilon
$$

for all $x, y \in X$. Then $T$ admits a unique fixed-point $x_{0} \in X$ and, for all $x \in X$, the sequence $\left\{T^{n}(x)\right\}$ converges to $x_{0}$.

Proposition 1.3 (see [17]). Let $(X, d)$ be a partially ordered metric space and $F: X \times X \rightarrow X$ be a given mapping. If the contraction (1.2) is satisfied, then $F$ is a generalized Meir-Keeler type contraction.

Motivated by the results of Bhaskar and Lakshmikantham [16], Lakshmikantham and Ćirić [17], and Samet [26], in this paper, we introduce the definition of g-Meir-Keelercontractive mappings and prove some coupled fixed-point theorems under a generalized $g$-Meir-Keeler contractive condition.

\section{Main Results}

Let $X$ be a nonempty set. We note that an element $(x, y) \in X \times X$ is called a coupled coincidence point of a mapping $F: X \times X \rightarrow X$ and $g: X \rightarrow X$ if $F(x, y)=g(x)$ and $F(y, x)=g(y)$ for all $x, y \in X$. Also, we say that $F$ and $g$ are commutative (or commuting) if $g(F(x, y))=$ $F(g(x), g(y))$ for all $x, y \in X$.

We introduce the following two definitions. 
Definition 2.1. Let $(X, \leq)$ be a partially ordered set and $F: X \times X \rightarrow X$ and $g: X \rightarrow X$. We say that $F$ has the mixed strict $g$-monotone property if, for any $x, y \in X$,

$$
\begin{array}{ll}
x_{1}, x_{2} \in X, & g\left(x_{1}\right)<g\left(x_{2}\right) \Longrightarrow F\left(x_{1}, y\right)<F\left(x_{2}, y\right), \\
y_{1}, y_{2} \in X, & g\left(y_{1}\right)<g\left(y_{2}\right) \Longrightarrow F\left(x, y_{1}\right)>F\left(x, y_{2}\right) .
\end{array}
$$

Definition 2.2. Let $(X, \leq)$ be a partially ordered set and $d$ be a metric on $X$. Let $F: X \times X \rightarrow X$ and $g: X \rightarrow X$ be two given mappings. We say that $F$ is a generalized g-Meir-Keeler type contraction if, for all $\epsilon>0$, there exists $\delta(\epsilon)>0$ such that, for all $x, y, u, v \in X$ with $g(x) \leq g(u)$ and $g(y) \geq g(v)$,

$$
\epsilon \leq \frac{1}{2}[d(g(x), g(u))+d(g(y), g(v))]<\epsilon+\delta(\epsilon) \Longrightarrow d(F(x, y), F(u, v))<\epsilon .
$$

Lemma 2.3. Let $(X, \leq)$ be a partially ordered set and $d$ be a metric on $X$. Let $F: X \times X \rightarrow X$ and $g: X \rightarrow X$ be two given mappings. If $F$ is a generalized g-Meir-Keeler type contraction, then we have

$$
d(F(x, y), F(u, v))<\frac{1}{2}[d(g(x), g(u))+d(g(y), g(v))]
$$

for all $x, y, u, v$ with $g(x)<g(u), g(y) \geq g(v)$ or $g(x) \leq g(u), g(y)>g(v)$.

Proof. Let $x, y, u, v \in X$ such that $g(x)<g(u)$ and $g(y) \geq g(v)$ or $g(x) \leq g(u)$ and $g(y)>$ $g(v)$. Then $d(g(x), g(u))+d(g(y), g(v))>0$. Since $F$ is a generalized $g$-Meir-Keeler type contraction, for $\epsilon=(1 / 2)[d(g(x), g(u))+d(g(y), g(v))]$, there exists $\delta(\epsilon)>0$ such that, for all $x_{0}, y_{0}, u_{0}, v_{0} \in X$ with $g\left(x_{0}\right) \leq g\left(u_{0}\right)$ and $g\left(y_{0}\right) \geq g\left(v_{0}\right)$,

$$
\epsilon \leq \frac{1}{2}\left[d\left(g\left(x_{0}\right), g\left(u_{0}\right)\right)+d\left(g\left(y_{0}\right), g\left(v_{0}\right)\right)\right]<\epsilon+\delta(\epsilon) \Longrightarrow d\left(F\left(x_{0}, y_{0}\right), F\left(u_{0}, v_{0}\right)\right)<\epsilon .
$$

Therefore, putting $x_{0}=x, y_{0}=y, u_{0}=u$ and $v_{0}=v$, we have

$$
d(F(x, y), F(u, v))<\frac{1}{2}[d(g(x), g(u))+d(g(y), g(v))] .
$$

This completes the proof.

From now on, we suppose that $(X, \leq)$ is a partially ordered set, and there exists a metric $d$ on $X$ such that $(X, d)$ is a complete metric space. 
Theorem 2.4. Let $F: X \times X \rightarrow X$ and $g: X \rightarrow X$ be such that $F(X \times X) \subseteq g(X), g$ is continuous and commutative with $F$. Also, suppose that

(a) F has the mixed strict g-monotone property;

(b) $F$ is a generalized g-Meir-keeler type contraction;

(c) there exist $x_{0}, y_{0} \in X$ such that $g\left(x_{0}\right)<F\left(x_{0}, y_{0}\right)$ and $g\left(y_{0}\right)>F\left(y_{0}, x_{0}\right)$.

Then there exist $x, y \in X$ such that $g(x)=F(x, y)$ and $g(y)=F(y, x)$; that is, $F$ and $g$ have $a$ coupled coincidence in $\mathrm{X} \times \mathrm{X}$.

Proof. Let $x_{0}, y_{0} \in X$ be such that $g\left(x_{0}\right)<F\left(x_{0}, y_{0}\right)$ and $g\left(y_{0}\right)>F\left(y_{0}, x_{0}\right)$. Since $F(X \times X) \subseteq$ $g(X)$, we can choose $x_{1}, y_{1} \in X$ such that $g\left(x_{1}\right)=F\left(x_{0}, y_{0}\right)$ and $g\left(y_{1}\right)=F\left(y_{0}, x_{0}\right)$. Again, from $F(X \times X) \subseteq g(X)$, we can choose $x_{2}, y_{2} \in X$ such that $g\left(x_{2}\right)=F\left(x_{1}, y_{1}\right)$ and $g\left(y_{2}\right)=F\left(y_{1}, x_{1}\right)$.

Continuing this process, we can construct the sequences $\left\{x_{n}\right\}$ and $\left\{y_{n}\right\}$ in $X$ such that

$$
g\left(x_{n+1}\right)=F\left(x_{n}, y_{n}\right), \quad g\left(y_{n+1}\right)=F\left(y_{n}, x_{n}\right)
$$

for all $n \geq 0$.

Now, we show that

$$
g\left(x_{n}\right)<g\left(x_{n+1}\right), \quad g\left(y_{n}\right)>g\left(y_{n+1}\right)
$$

for all $n \geq 0$. For $n=0$, we have

$$
g\left(x_{0}\right)<F\left(x_{0}, y_{0}\right)=g\left(x_{1}\right), \quad g\left(y_{0}\right)>F\left(y_{0}, x_{0}\right)=g\left(y_{1}\right) .
$$

Since $F$ has the mixed strict $g$-monotone property, then we have

$$
\begin{aligned}
& g\left(x_{0}\right)<g\left(x_{1}\right) \Longrightarrow F\left(x_{0}, y_{1}\right)<F\left(x_{1}, y_{1}\right) \\
& g\left(y_{0}\right)>g\left(y_{1}\right) \Longrightarrow F\left(x_{0}, y_{0}\right)<F\left(x_{0}, y_{1}\right)
\end{aligned}
$$

It follows that $F\left(x_{0}, y_{0}\right)<F\left(x_{1}, y_{1}\right)$, that is, $g\left(x_{1}\right)<g\left(x_{2}\right)$.

Similarly, we have

$$
\begin{gathered}
g\left(y_{1}\right)<g\left(y_{0}\right) \Longrightarrow F\left(y_{1}, x_{0}\right)<F\left(y_{0}, x_{0}\right), \\
g\left(x_{1}\right)>g\left(x_{0}\right) \Longrightarrow F\left(y_{1}, x_{1}\right)<F\left(y_{1}, x_{0}\right)
\end{gathered}
$$

Thus it follows that $F\left(y_{1}, x_{1}\right)<F\left(y_{0}, x_{0}\right)$, that is, $g\left(y_{2}\right)<g\left(y_{1}\right)$.

Again, we have

$$
\begin{aligned}
& g\left(x_{1}\right)<g\left(x_{2}\right) \Longrightarrow F\left(x_{1}, y_{2}\right)<F\left(x_{2}, y_{2}\right) \\
& g\left(y_{1}\right)>g\left(y_{2}\right) \Longrightarrow F\left(x_{1}, y_{1}\right)<F\left(x_{1}, y_{2}\right)
\end{aligned}
$$

Thus it follows that $F\left(x_{1}, y_{1}\right)<F\left(x_{2}, y_{2}\right)$, that is, $g\left(x_{2}\right)<g\left(x_{3}\right)$. 
Similarly, we have

$$
\begin{gathered}
g\left(y_{2}\right)<g\left(y_{1}\right) \Longrightarrow F\left(y_{2}, x_{1}\right)<F\left(y_{1}, x_{1}\right) \\
g\left(x_{2}\right)>g\left(x_{1}\right) \Longrightarrow F\left(y_{2}, x_{2}\right)<F\left(y_{2}, x_{1}\right)
\end{gathered}
$$

Thus it follows that $F\left(y_{2}, x_{2}\right)<F\left(y_{1}, x_{1}\right)$, that is, $g\left(y_{3}\right)<g\left(y_{2}\right)$.

Continuing this process for each $n \geq 1$, we get the following:

$$
\begin{aligned}
& g\left(x_{0}\right)<g\left(x_{1}\right)<g\left(x_{2}\right)<\cdots<g\left(x_{n}\right)<g\left(x_{n+1}\right)<\cdots, \\
& g\left(y_{0}\right)>g\left(y_{1}\right)>g\left(y_{2}\right)>\cdots g\left(y_{n}\right)>g\left(y_{n+1}\right)>\cdots .
\end{aligned}
$$

Denote that

$$
\delta_{n}:=d\left(g\left(x_{n}\right), g\left(x_{n+1}\right)\right)+d\left(g\left(y_{n}\right), g\left(y_{n+1}\right)\right) .
$$

Since $g\left(x_{n-1}\right)<g\left(x_{n}\right)$ and $g\left(y_{n-1}\right)>g\left(y_{n}\right)$, it follows from (2.6) and Lemma 2.3 that

$$
\begin{aligned}
d\left(g\left(x_{n}\right), g\left(x_{n+1}\right)\right) & =d\left(F\left(x_{n-1}, y_{n-1}\right), F\left(x_{n}, y_{n}\right)\right) \\
& <\frac{1}{2}\left[d\left(g\left(x_{n-1}\right), g\left(x_{n}\right)\right)+d\left(g\left(y_{n-1}\right), g\left(y_{n}\right)\right)\right] .
\end{aligned}
$$

Since $g\left(y_{n}\right)<g\left(y_{n-1}\right)$ and $g\left(x_{n}\right)>g\left(x_{n-1}\right)$, it follows from (2.6) and Lemma 2.3 that

$$
\begin{aligned}
d\left(g\left(y_{n+1}\right), g\left(y_{n}\right)\right) & =d\left(F\left(y_{n}, x_{n}\right), F\left(y_{n-1}, x_{n-1}\right)\right) \\
& <\frac{1}{2}\left[d\left(g\left(y_{n}\right), g\left(y_{n-1}\right)\right)+d\left(g\left(x_{n}\right), g\left(x_{n-1}\right)\right)\right] .
\end{aligned}
$$

Thus it follows from (2.14)-(2.16) that $\delta_{n}<\delta_{n-1}$. This means that the sequence $\left\{\delta_{n} / 2\right\}$ is monotone decreasing. Therefore, there exists $\delta^{*} \geq 0$ such that $\lim _{n \rightarrow \infty} \delta_{n} / 2=\delta^{*}$, that is,

$$
\lim _{n \rightarrow \infty} \frac{1}{2}\left[d\left(g\left(x_{n}\right), g\left(x_{n+1}\right)\right)+d\left(g\left(y_{n}\right), g\left(y_{n+1}\right)\right)\right]=\delta^{*}
$$

Now, we show that $\delta^{*}=0$. Suppose that $\delta^{*}>0$ hold. Let $\delta^{*}=\epsilon$. Then there exists a positive integer $m$ such that

$$
\epsilon \leq \frac{1}{2}\left[d\left(g\left(x_{m}\right), g\left(x_{m+1}\right)\right)+d\left(g\left(y_{m}\right), g\left(y_{m+1}\right)\right)\right]<\epsilon+\delta(\epsilon) .
$$

Then, by using (2.7) and the condition (b), we have

$$
d\left(F\left(x_{m}, y_{m}\right), F\left(x_{m+1}, y_{m+1}\right)\right)<\epsilon
$$


and so, by (2.6), we have

$$
d\left(g\left(x_{m+1}\right), g\left(x_{m+2}\right)\right)<\epsilon .
$$

On the other hand, by (2.15), we have

$$
\frac{1}{2}\left[d\left(g\left(x_{m}\right), g\left(x_{m+1}\right)\right)+d\left(g\left(y_{m}\right), g\left(y_{m+1}\right)\right)\right]<\epsilon,
$$

which is a contradiction with (2.18). Thus we have $\epsilon=\delta^{*}=0$, that is,

$$
\lim _{n \rightarrow \infty} \frac{1}{2}\left[d\left(g\left(x_{n}\right), g\left(x_{n+1}\right)\right)+d\left(g\left(y_{n}\right), g\left(y_{n+1}\right)\right)\right]=0,
$$

that is,

$$
\lim _{n \rightarrow \infty} \delta_{n}=0
$$

Now, we prove that $\left\{g\left(x_{n}\right)\right\}$ and $\left\{g\left(y_{n}\right)\right\}$ are Cauchy sequences in X. Suppose that at least one of $\left\{g\left(x_{n}\right)\right\}$ or $\left\{g\left(y_{n}\right)\right\}$ is not a Cauchy sequence. Then there exist $\epsilon>0$ and two subsequences $\left\{l_{k}\right\},\left\{m_{k}\right\}$ of integers such that $m_{k}>l_{k} \geq k$ and

$$
d\left(g\left(x_{l_{k}}\right), g\left(x_{m_{k}}\right)\right) \geq \frac{\epsilon}{2}, \quad d\left(g\left(y_{l_{k}}\right), g\left(y_{m_{k}}\right)\right) \geq \frac{\epsilon}{2}
$$

for all $k \geq 1$. Thus we have

$$
r_{k}=d\left(g\left(x_{l_{k}}\right), g\left(x_{m_{k}}\right)\right)+d\left(g\left(y_{l_{k}}\right), g\left(y_{m_{k}}\right)\right) \geq \epsilon
$$

for all $k \geq 1$. Let $m_{k}$ be the smallest number exceeding $l_{k}$ such that (2.25) holds. Then we have

$$
d\left(g\left(x_{l_{k}}\right), g\left(x_{m_{k}-1}\right)\right)+d\left(g\left(y_{l_{k}}\right), g\left(y_{m_{k}-1}\right)\right)<\epsilon .
$$

Thus, from (2.14), (2.25), (2.26) and the triangle inequality, it follows that

$$
\begin{aligned}
\epsilon \leq & r_{k} \\
\leq & d\left(g\left(x_{1_{k}}\right), g\left(x_{m_{k}-1}\right)\right)+d\left(g\left(x_{m_{k}-1}\right), g\left(x_{m_{k}}\right)\right) \\
& +d\left(g\left(y_{l_{k}}\right), g\left(y_{m_{k}-1}\right)\right)+d\left(g\left(y_{m_{k}-1}\right), g\left(y_{m_{k}}\right)\right) \\
< & \epsilon+\delta_{m_{k}-1}
\end{aligned}
$$

and so

$$
\epsilon \leq \lim _{k \rightarrow \infty} r_{k} \leq \lim _{k \rightarrow \infty}\left(\epsilon+\delta_{m_{k}-1}\right)
$$


Hence, by (2.23), we have

$$
\lim _{k \rightarrow \infty} r_{k}=\epsilon^{+}
$$

It follows from (2.6), (2.14), and the triangle inequality that

$$
\begin{aligned}
r_{k}= & d\left(g\left(x_{l_{k}}\right), g\left(x_{m_{k}}\right)\right)+d\left(g\left(y_{l_{k}}\right), g\left(y_{m_{k}}\right)\right) \\
\leq & d\left(g\left(x_{l_{k}}\right), g\left(x_{l_{k}+1}\right)\right)+d\left(g\left(x_{l_{k}+1}\right), g\left(x_{m_{k}+1}\right)\right)+d\left(g\left(x_{m_{k}+1}\right), g\left(x_{m_{k}}\right)\right) \\
& +d\left(g\left(y_{l_{k}}\right), g\left(y_{l_{k}+1}\right)\right)+d\left(g\left(y_{l_{k}+1}\right), g\left(y_{m_{k}+1}\right)\right)+d\left(g\left(y_{m_{k}+1}\right), g\left(y_{m_{k}}\right)\right) \\
= & \delta_{l_{k}}+\delta_{m_{k}}+d\left(g\left(x_{l_{k}+1}\right), g\left(x_{m_{k}+1}\right)\right)+d\left(g\left(y_{l_{k}+1}\right), g\left(y_{m_{k}+1}\right)\right) \\
= & \delta_{l_{k}}+\delta_{m_{k}}+d\left(F\left(x_{l_{k}}, y_{l_{k}}\right), F\left(x_{m_{k}}, y_{m_{k}}\right)\right)+d\left(F\left(y_{l_{k}}, x_{l_{k}}\right), F\left(y_{m_{k}}, x_{m_{k}}\right)\right) .
\end{aligned}
$$

Form (2.13) we have $g\left(x_{l_{k}}\right)<g\left(x_{m_{k}}\right)$ and $g\left(y_{l_{k}}\right)>g\left(y_{m_{k}}\right)$. Now, it follows from Lemma 2.3 and (2.30) that

$$
r_{k}<\delta_{l_{k}}+\delta_{m_{k}}+d\left(g\left(x_{l_{k}}\right), g\left(x_{m_{k}}\right)\right)+d\left(g\left(y_{l_{k}}\right), g\left(y_{m_{k}}\right)\right)
$$

that is,

$$
r_{k}<\delta_{l_{k}}+\delta_{m_{k}}+r_{k}
$$

This is a contradiction. Therefore, $\left\{g\left(x_{n}\right)\right\}$ and $\left\{g\left(y_{n}\right)\right\}$ are Cauchy sequences. Since $X$ is complete, there exist $x, y \in X$ such that

$$
\lim _{n \rightarrow \infty} g\left(x_{n}\right)=x, \quad \lim _{n \rightarrow \infty} g\left(y_{n}\right)=y
$$

Since $\left\{g\left(x_{n}\right)\right\}$ is monotone increasing and $\left\{g\left(y_{n}\right)\right\}$ is monotone decreasing, we have

$$
g\left(x_{n}\right)<x, \quad g\left(y_{n}\right)>y
$$

for all $n \geq 1$. Thus it follows from (2.33) and the continuity of $g$ that

$$
\lim _{n \rightarrow \infty} g\left(g\left(x_{n}\right)\right)=g(x), \quad \lim _{n \rightarrow \infty} g\left(g\left(y_{n}\right)\right)=g(y)
$$

Thus, for all $m \geq 1$, there exists a positive integer $n_{0}$ such that, for all $n \geq n_{0}$,

$$
d\left(g\left(g\left(x_{n}\right)\right), g(x)\right)<\frac{1}{4 m}, \quad d\left(g\left(g\left(y_{n}\right)\right), g(y)\right)<\frac{1}{4 m} .
$$


Hence, from (2.6), the commutativity of $F$ and $g$ and the triangle inequality, we have

$$
\begin{aligned}
d(F(x, y), g(x)) & \leq d\left(F(x, y), g\left(g\left(x_{n}\right)\right)\right)+d\left(g\left(g\left(x_{n}\right)\right), g(x)\right) \\
& =d\left(F(x, y), g\left(F\left(x_{n-1}, y_{n-1}\right)\right)\right)+d\left(g\left(g\left(x_{n}\right)\right), g(x)\right) \\
& =d\left(F(x, y), F\left(g\left(x_{n-1}\right), g\left(y_{n-1}\right)\right)\right)+d\left(g\left(g\left(x_{n}\right)\right), g(x)\right) .
\end{aligned}
$$

Thus, it follows from (2.34), (2.36), and Lemma 2.3 that

$$
\begin{aligned}
d & (F(x, y), g(x)) \\
& <\frac{1}{2}\left[d\left(g\left(g\left(x_{n-1}\right)\right), g(x)\right)+d\left(g\left(g\left(y_{n-1}\right)\right), g(y)\right)\right]+d\left(g\left(g\left(x_{n}\right)\right), g(x)\right) \\
& <\frac{1}{8 m}+\frac{1}{8 m}+\frac{1}{4 m} \\
& =\frac{1}{2 m} \longrightarrow 0
\end{aligned}
$$

as $m \rightarrow \infty$. Therefore, we have $F(x, y)=g(x)$. Similarly, we can show that $F(y, x)=g(y)$. This means that $F$ and $g$ have a coupled coincidence point in $X \times X$. This completes the proof.

Corollary 2.5. Let $F: X \times X \rightarrow X$ be a mapping satisfying the following conditions:

(a) F has the mixed strict monotone property;

(b) F is a generalized Meir-Keeler type contraction;

(c) there exists $x_{0}, y_{0} \in X$ such that $x_{0}<F\left(x_{0}, y_{0}\right)$ and $y_{0}>F\left(y_{0}, x_{0}\right)$.

Then there exist $x, y \in X$ such that $x=F(x, y)$ and $y=F(y, x)$.

Proof. The conclusion follows from Theorem 2.4 by putting $g=I$ (: the identity mapping) on $X$.

Now, we introduce the product space $X \times X$ with the following partial order: for all $(x, y),(u, v) \in X \times X$,

$$
(u, v) \leq(x, y) \Longleftrightarrow u<x, \quad v \geq y
$$

Theorem 2.6. Suppose that all the hypotheses of Theorem 2.4 hold and, further, for all $(x, y),\left(x^{*}, y^{*}\right) \in X \times X$, there exists $(u, v) \in X \times X$ such that $(F(u, v), F(v, u))$ is comparable with $(F(x, y), F(y, x))$ and $\left(F\left(x^{*}, y^{*}\right), F\left(y^{*}, x^{*}\right)\right)$. Then $F$ and $g$ have a unique coupled common fixed-point, that is, there exists a unique $(x, y) \in X \times X$ such that

$$
x=g(x)=F(x, y), \quad y=g(y)=F(y, x) .
$$


Proof. By Theorem 2.4, the set of coupled coincidences of the mapping $F$ and $g$ is nonempty. that is, if First, we show that, if $(x, y)$ and $\left(x^{*}, y^{*}\right)$ are coupled coincidence points of $F$ and $g$,

$$
g(x)=F(x, y), \quad g(y)=F(y, x), \quad g\left(x^{*}\right)=F\left(x^{*}, y^{*}\right), \quad g\left(y^{*}\right)=F\left(y^{*}, x^{*}\right),
$$

then we have

$$
g(x)=g\left(x^{*}\right), \quad g(y)=g\left(y^{*}\right)
$$

Put $u_{0}=u, v_{0}=v$ and choose $u_{1}, v_{1} \in X$ such that $g\left(u_{1}\right)=F\left(u_{0}, v_{0}\right)$ and $g\left(v_{1}\right)=F\left(v_{0}, u_{0}\right)$. Then, similarly as in the proof of Theorem 2.4, we can inductively define the sequences $\left\{g\left(u_{n}\right)\right\}$ and $\left\{g\left(v_{n}\right)\right\}$ such that

$$
g\left(u_{n+1}\right)=F\left(u_{n}, v_{n}\right), \quad g\left(v_{n+1}\right)=F\left(v_{n}, u_{n}\right)
$$

for all $n \geq 0$. Also, if we set $x_{0}=x, y_{0}=y, x_{0}^{*}=x^{*}$, and $y_{0}^{*}=y^{*}$, then we can define the sequences $\left\{g\left(x_{n}\right)\right\},\left\{g\left(y_{n}\right)\right\},\left\{g\left(x_{n}^{*}\right)\right\}$, and $\left\{g\left(y_{n}^{*}\right)\right\}$ as follows:

$$
\begin{array}{ll}
g\left(x_{n+1}\right)=F\left(x_{n}, y_{n}\right), & g\left(y_{n+1}\right)=F\left(y_{n}, x_{n}\right), \\
g\left(x_{n+1}^{*}\right)=F\left(x_{n}^{*}, y_{n}^{*}\right), & g\left(y_{n+1}^{*}\right)=F\left(y_{n}^{*}, x_{n}^{*}\right)
\end{array}
$$

for all $n \geq 0$. Since

$$
\begin{gathered}
(F(x, y), F(y, x))=\left(g\left(x_{1}\right), g\left(y_{1}\right)\right)=(g(x), g(y)), \\
(F(u, v), F(v, u))=\left(g\left(u_{1}\right), g\left(v_{1}\right)\right)
\end{gathered}
$$

are comparable each other, then $g(x)<g\left(u_{1}\right)$ and $g(y) \geq g\left(v_{1}\right)$. It is easy to show that $(g(x), g(y))$, and $\left(g\left(u_{n}\right), g\left(v_{n}\right)\right)$ are comparable each other, that is, $g(x)<g\left(u_{n}\right)$ and $g(y) \geq$ $g\left(v_{n}\right)$ for all $n \geq 1$. Thus it follows from Lemma 2.3 that

$$
\begin{aligned}
& d\left(g(x), g\left(u_{n+1}\right)\right)+d\left(g(y), g\left(v_{n+1}\right)\right) \\
& \quad=d\left(F(x, y), F\left(u_{n}, v_{n}\right)\right)+d\left(F(y, x), F\left(v_{n}, u_{n}\right)\right) \\
& \quad<\frac{1}{2}\left[d\left(g(x), g\left(u_{n}\right)\right)+d\left(g(y), g\left(v_{n}\right)\right)\right]+\frac{1}{2}\left[d\left(g(y), g\left(v_{n}\right)\right)+d\left(g(x), g\left(u_{n}\right)\right)\right] \\
& \quad=d\left(g(x), g\left(u_{n}\right)\right)+d\left(g(y), g\left(v_{n}\right)\right)
\end{aligned}
$$

and so

$$
\frac{1}{2}\left[d\left(g(x), g\left(u_{n+1}\right)\right)+d\left(g(y), g\left(v_{n+1}\right)\right)\right]<\frac{1}{2^{n}}\left[d\left(g(x), g\left(u_{1}\right)\right)+d\left(g(y), g\left(v_{1}\right)\right)\right] \longrightarrow 0
$$


as $n \rightarrow \infty$. Therefore, we have

$$
\lim _{n \rightarrow \infty} d\left(g(x), g\left(u_{n+1}\right)\right)=0, \quad \lim _{n \rightarrow \infty} d\left(g(y), g\left(v_{n+1}\right)\right)=0 .
$$

Similarly, we can prove that

$$
\lim _{n \rightarrow \infty} d\left(g\left(x^{*}\right), g\left(u_{n+1}\right)\right)=0, \quad \lim _{n \rightarrow \infty} d\left(g\left(y^{*}\right), g\left(v_{n+1}\right)\right)=0 .
$$

Thus, by the triangle inequality, (2.48) and (2.49), we have

$$
\begin{aligned}
& d\left(g(x), g\left(x^{*}\right)\right) \leq d\left(g(x), g\left(u_{n+1}\right)\right)+d\left(g\left(x^{*}\right), g\left(u_{n+1}\right)\right) \longrightarrow 0, \\
& d\left(g(y), g\left(y^{*}\right)\right) \leq d\left(g(y), g\left(v_{n+1}\right)\right)+d\left(g\left(y^{*}\right), g\left(v_{n+1}\right)\right) \longrightarrow 0
\end{aligned}
$$

as $n \rightarrow \infty$, which imply that $g(x)=g\left(x^{*}\right)$ and $g(y)=g\left(y^{*}\right)$.

Now, we prove that $g(x)=x$ and $g(y)=y$. Denote that $g(x)=z$ and $g(x)=w$. Since $g(x)=F(x, y)$ and $g(y)=F(y, x)$, by the commutativity of $F$ and $g$, we have

$$
\begin{gathered}
g(z)=g(g(x))=g(F(x, y))=F(g(x), g(y))=F(z, w), \\
g(w)=g(g(y))=g(F(y, x))=F(g(y), g(x))=F(w, z) .
\end{gathered}
$$

Thus, $(z, \mathrm{w})$ is a coupled coincidence point of $F$ and $g$.

Putting $x^{*}=z$ and $y^{*}=w$ in (2.52), it follows from (2.42) that

$$
z=g(x)=g\left(x^{*}\right)=g(z), \quad w=g(y)=g\left(y^{*}\right)=g(w)
$$

and so, from (2.51) and (2.52),

$$
z=g(z)=F(z, w), \quad w=g(w)=F(w, z)
$$

Therefore, $(z, w)$ is a coupled common fixed-point of $F$ and $g$.

Finally, to prove the uniqueness of the coupled common fixed-point of $F$ and $g$, assume that $(p, q)$ is another coupled common fixed-point of $F$ and $g$. Then, by (2.42), we have $p=$ $\mathrm{g}(p)=g(z)=z$ and $q=g(q)=g(w)=w$. This completes the proof.

Corollary 2.7. Suppose that all the hypotheses of Corollary 2.5 hold and, further, for all $(x, y)$ and $\left(x^{*}, y^{*}\right) \in X \times X$, there exists $(u, v) \in X \times X$ that is comparable with $(x, y)$ and $\left(x^{*}, y^{*}\right)$. Then there exists a unique $x \in X$ such that $x=F(x, x)$. 


\section{Applications}

Now, we give some applications of the main results in Section 2.

Theorem 3.1. Let $F: X \times X \rightarrow X$ and $g: X \rightarrow X$ be two given mappings. Assume that there exists a function $\varphi:[0,+\infty) \rightarrow[0,+\infty)$ satisfying the following conditions:

(a) $\varphi(0)=0$ and $\varphi(t)>0$ for any $t>0$;

(b) $\varphi$ is nondecreasing and right continuous;

(c) for any $\epsilon>0$, there exists $\delta(\epsilon)>0$ such that, for all $x, y, u, v \in X$ with $g(x) \leq g(u)$ and $g(y) \geq g(v)$

$$
\epsilon \leq \varphi\left(\frac{1}{2}[d(g(x), g(u))+d(g(y), g(v))]\right)<\epsilon+\delta(\epsilon) \Longrightarrow \varphi[d(F(x, y), F(u, v))]<\epsilon .
$$

Then $F$ is a generalized g-Meir-Keeler type contraction.

Proof. For any $\epsilon>0$, it follows from (a) that $\varphi(\epsilon)>0$ and so there exists $\alpha>0$ such that, for all $u, v, u^{*}, v^{\star} \in X$ with $g(u) \leq g\left(u^{*}\right)$ and $g(v) \geq g\left(v^{*}\right)$,

$$
\begin{aligned}
\varphi(\epsilon) & \leq \varphi\left(\frac{1}{2}\left[d\left(g(u), g\left(u^{*}\right)\right)+d\left(g(v), g\left(v^{*}\right)\right)\right]\right)<\varphi(\epsilon)+\alpha \\
& \Longrightarrow \varphi\left[d\left(F(u, v), F\left(u^{*}, v^{*}\right)\right)\right]<\varphi(\epsilon) .
\end{aligned}
$$

From the right continuity of $\varphi$, there exists $\delta>0$ such that $\varphi(\epsilon+\delta)<\varphi(\epsilon)+\alpha$. For any $x, y, u, v \in X$ such that $g(x) \leq g(u), g(y) \geq g(v)$ and

$$
\epsilon \leq \frac{1}{2}[d(g(x), g(u))+d(g(y), g(v))]<\epsilon+\delta,
$$

since $\varphi$ is nondecreasing function, we get the following:

$$
\varphi(\epsilon) \leq \varphi\left(\frac{1}{2}[d(g(x), g(u))+d(g(y), g(v))]\right)<\varphi(\epsilon+\alpha)<\varphi(\epsilon)+\alpha .
$$

By (3.2), we have $\varphi[d(F(x, y), F(u, v))]<\varphi(\epsilon)$ and so $d(F(x, y), F(u, v))<\epsilon$. Therefore, it follows that $F$ is a generalized $g$-Meir-Keeler type contraction. This completes the proof.

Corollary 3.2 (see [26, Theorem 3.1]). Let $F: X \times X \rightarrow X$ be a given mapping. Assume that there exists a function $\varphi:[0,+\infty) \rightarrow[0,+\infty)$ satisfying the following conditions:

(a) $\varphi(0)=0$ and $\varphi(t)>0$ for any $t>0$;

(b) $\varphi$ is nondecreasing and right continuous; 
(c) for any $\epsilon>0$, there exists $\delta(\epsilon)>0$ such that $x \leq u, y \geq v$ and

$$
\epsilon \leq \varphi\left(\frac{1}{2}[d(x, u)+d(y, v)]\right)<\epsilon+\delta(\epsilon) \Longrightarrow \varphi[d(F(x, y), F(u, v))]<\epsilon .
$$

Then $F$ is a generalized Meir-Keeler type contraction.

The following result is an immediate consequence of Theorems 2.4 and 3.1.

Corollary 3.3. Let $F: X \times X \rightarrow X$ and $g: X \rightarrow X$ be two given mappings such that $F(X \times X) \subseteq$ $g(X), g$ is continuous and commutative with $F$. Also, suppose that

(a) F has the mixed strict g-monotone property;

(b) for any $\epsilon>0$, there exists $\delta(\epsilon)>0$ such that, for all $x, y, u, v \in X$ with $g(x) \leq g(u)$ and $g(y) \geq g(v)$,

$$
\epsilon \leq \int_{0}^{(1 / 2)[d(g(x), g(u))+d(g(y), g(v))]} \varphi(t) d t<\epsilon+\delta(\epsilon) \Longrightarrow \int_{0}^{d(F(x, y), F(u, v))} \varphi(t) d t<\epsilon,
$$

where $\varphi$ is a locally integrable function from $[0,+\infty)$ into itself satisfying the following condition:

$$
\int_{0}^{s} \varphi(t) d t>0
$$

for all $s>0$;

(c) there exist $x_{0}, y_{0} \in X$ such that $g\left(x_{0}\right)<F\left(x_{0}, y_{0}\right)$ and $g\left(y_{0}\right)>F\left(y_{0}, x_{0}\right)$.

Then there exists $(x, y) \in X \times X$ such that $g(x)=F(x, y)$ and $g(y)=F(y, x)$. Moreover, if $g\left(x_{0}\right)$ and $g\left(y_{0}\right)$ are comparable to each other, then $F$ and $g$ have a unique coupled common fixed-point in $\mathrm{X} \times \mathrm{X}$.

Corollary 3.4. Let $F: X \times X \rightarrow X$ be a mapping satisfying the following conditions:

(a) F has the mixed strict monotone property;

(b) for any $\epsilon>0$, there exists $\delta(\epsilon)>0$ such that $x \leq u, y \geq v$ and

$$
\epsilon \leq \int_{0}^{(1 / 2)[d(x, u)+d(y, v)]} \varphi(t) d t<\epsilon+\delta(\epsilon) \Longrightarrow \int_{0}^{[d(F(x, y), F(u, v))]} \varphi(t) d t<\epsilon,
$$


where $\varphi$ is a locally integrable function from $[0,+\infty)$ into itself satisfying

$$
\int_{0}^{s} \varphi(t) d t>0
$$

for all $s>0$;

(c) there exist $x_{0}, y_{0} \in X$ such that $x_{0}<F\left(x_{0}, y_{0}\right)$ and $y_{0}>F\left(y_{0}, x_{0}\right)$.

Then there exists $(x, y) \in X \times X$ such that $x=F(x, y)$ and $y=F(y, x)$. Moreover, if $x_{0}$ and $y_{0}$ are comparable to each other, then $F$ has a unique coupled common fixed-point in $X \times X$.

Corollary 3.5. Let $F: X \times X \rightarrow X$ and $g: X \rightarrow X$ be two given mappings such that $F(X \times X) \subseteq$ $g(X), g$ is continuous and commutes with $F$. Also, suppose that

(a) F has the mixed strict g-monotone property;

(b) for any $x, y, u, v \in X$ with $g(x) \leq g(u)$ and $g(y) \geq g(v)$,

$$
\int_{0}^{[d(F(x, y), F(u, v))]} \varphi(t) d t \leq k \int_{0}^{(1 / 2)[d(g(x), g(u))+d(g(y), g(v))]} \varphi(t) d t,
$$

where $k \in(0,1)$ and $\varphi$ is a locally integrable function from $[0,+\infty)$ into itself satisfying

$$
\int_{0}^{s} \varphi(t) d t>0
$$

for all $s>0$;

(c) there exist $x_{0}, y_{0} \in X$ such that $g\left(x_{0}\right)<F\left(x_{0}, y_{0}\right)$ and $g\left(y_{0}\right)>F\left(y_{0}, x_{0}\right)$.

Then there exists $(x, y) \in X \times X$ such that $g(x)=F(x, y)$ and $g(y)=F(y, x)$. Moreover, if $g\left(x_{0}\right)$ and $g\left(y_{0}\right)$ are comparable to each other, then $F$ and $g$ have a unique coupled common fixed-point in $X \times X$.

Proof. For any $\epsilon>0$, if we take $\delta(\epsilon)=(1 / k-1) \epsilon$ and apply Corollary 3.3, then we can get the conclusion.

Corollary 3.6. Let $F: X \times X \rightarrow X$ be a mapping satisfying the following conditions:

(a) F has the mixed strict monotone property,

(b) for any $x, y, u, v \in X$ with $x \leq u$ and $y \geq v$,

$$
\int_{0}^{d(F(x, y), F(u, v))} \varphi(t) d t \leq k \int_{0}^{(1 / 2)[d(x, u)+d(y, v)]} \varphi(t) d t
$$


where $k \in(0,1)$ and $\varphi$ is a locally integrable function from $[0,+\infty)$ into itself satisfying

$$
\int_{0}^{s} \varphi(t) d t>0
$$

for all $s>0$;

(c) there exist $x_{0}, y_{0} \in X$ such that $x_{0}<F\left(x_{0}, y_{0}\right)$ and $y_{0}>F\left(y_{0}, x_{0}\right)$.

Then there exist $x, y \in X$ such that $x=F(x, y)$ and $y=F(y, x)$. Moreover, if $x_{0}$ and $y_{0}$ are comparable to each other, then $F$ has a unique coupled common fixed-point in $X \times X$.

Finally, by using the above results, we show the existence of solutions for the following integral equation:

$$
\begin{aligned}
(x(t), y(t))= & \left(\int_{0}^{T} G(t, s)[(f(s, x(s))+\lambda x(s))-(f(s, y(s))+\lambda y(s))] d s,\right. \\
& \left.\int_{0}^{T} G(t, s)[(f(s, y(s))+\lambda y(s))-(f(s, x(s))+\lambda x(s))] d s\right),
\end{aligned}
$$

where $x, y \in C(I, \mathbb{R})$ (: the set of continuous functions from $I$ into $\mathbb{R}), T>0, f: I \times \mathbb{R} \rightarrow \mathbb{R}$ is a continuous function and

$$
G(t, s)= \begin{cases}\frac{e^{\lambda(T+s-t)}}{e^{\lambda T}-1}, & \text { if } 0 \leq s<t \leq T ; \\ \frac{e^{\lambda(s-t)}}{e^{\lambda T}-1}, & \text { if } 0 \leq t<s \leq T .\end{cases}
$$

Definition 3.7. A lower solution for the integral equation (3.14) is an element $(\alpha, \beta) \in C^{1}(I, \mathbb{R}) \times$ $C^{1}(I, \mathbb{R})$ such that

$$
\begin{array}{ll}
\alpha^{\prime}(t)+\lambda \beta(t) \leq f(t, \alpha(t))-f(t, \beta(t)), & \alpha(0)<\alpha(T), \\
\beta^{\prime}(t)+\lambda \alpha(t) \geq f(t, \beta(t))-f(t, \alpha(t)), & \beta(0) \geq \beta(T),
\end{array}
$$

where $C^{1}(I, \mathbb{R})$ denotes the set of differentiable functions from $I$ into $\mathbb{R}$.

Now, we prove the existence of solutions for the integral equation (3.14) by using the existence of a lower solution for the integral equation (3.14).

Theorem 3.8. Let $A$ be the class of the functions $\varphi:[0, \infty) \rightarrow[0, \infty)$ satisfying the following conditions:

(a) $\varphi$ is increasing;

(b) for any $x \geq 0$, there exists $k \in[0,1)$ such that $\varphi(x)<(k / 2) x$. 
In the integral equation (3.14), suppose that there exists $\lambda>0$ such that, for all $x, y \in \mathbb{R}$ with $y>x$,

$$
0<f(t, y)+\lambda y-[f(t, x)+\lambda x] \leq \lambda \varphi(y-x)
$$

where $\varphi \in \mathcal{A}$. If a lower solution of the integral equation (3.14) exists, then a solution of the integral equation (3.14) exists.

Proof. Define a mapping $F: C(I, \mathbb{R}) \times C(I, \mathbb{R}) \rightarrow C(I, \mathbb{R})$ by

$$
F(x(t), y(t))=\int_{0}^{T} G(t, s)[(f(s, x(s))+\lambda x(s))-(f(s, y(s))+\lambda y(s))] d s
$$

Note that, if $(x(t), y(t)) \in C(I, \mathbb{R}) \times C(I, \mathbb{R})$ is a coupled fixed-point of $F$, then $(x(t), y(t))$ is a solution of the integral equation (3.14).

Now, we check the hypotheses in Corollary 2.5 as follows:

(1) $X \times X=C(I, \mathbb{R}) \times C(I, \mathbb{R})$ is a partially ordered set if we define the order relation in $X \times X$ as follows:

$$
(u(t), v(t)) \leq(x(t), y(t)) \quad \text { iff } u(t)<x(t), v(t) \geq y(t)
$$

for all $(x(t), y(t)),(u(t), v(t)) \in X \times X$ and $t \in I$.

(2) $(X, d)$ is a complete metric space if we define a metric $d$ as follows:

$$
d(x(t), y(t))=\sup _{t \in I}\{|x(t)-y(t)|: x(t), y(t) \in X\}
$$

(3) The mapping $F$ has the mixed strict monotone property. In fact, by hypothesis, if $x_{2}>x_{1}$, then we have

$$
f\left(t, x_{2}\right)+\lambda x_{2}>f\left(t, x_{1}\right)+\lambda x_{1}
$$

which implies that, for any $t \in I$,

$$
\begin{aligned}
& \int_{0}^{T}\left[f\left(s, x_{2}(s)\right)+\lambda x_{2}(s)-f(s, y(s))-\lambda y(s)\right] G(t, s) d s \\
& \quad>\int_{0}^{T}\left[f\left(s, x_{1}(s)\right)+\lambda x_{1}(s)-f(s, y(s))-\lambda y(s)\right] G(t, s) d s,
\end{aligned}
$$

that is,

$$
F\left(x_{2}(t), y(t)\right)>F\left(x_{1}(t), y(t)\right) \text {. }
$$


Similarly, if $y_{1}<y_{2}$, then we have

$$
f\left(t, y_{2}\right)+\lambda y_{2}>f\left(t, y_{1}\right)+\lambda y_{1}
$$

which implies that, for any $t \in I$,

$$
\begin{aligned}
\int_{0}^{T}\left[f(s, x(s))+\lambda x(s)-f\left(s, y_{2}(s)\right)-\lambda y_{2}(s)\right] G(t, s) d s \\
\quad<\int_{0}^{T}\left[f(s, x(s))+\lambda x(s)-f\left(s, y_{1}(s)\right)-\lambda y_{1}(s)\right] G(t, s) d s,
\end{aligned}
$$

that is,

$$
F\left(x(t), y_{2}(t)\right)<F\left(x(t), y_{1}(t)\right) \text {. }
$$

Now, we show that $F$ satisfies (1.2). In fact, let $(x, y) \leq(u, v)$ and $t \in I$. Then we have

$$
\begin{aligned}
& d(F(x(t), y(t)), F(u(t), v(t))) \\
& =\sup \{|F(x(t), y(t))-F(u(t), v(t))|: t \in I\} \\
& =\sup _{t \in I}\left\{\mid \int_{0}^{T} G(t, s)[f(s, x(s))+\lambda x(s)-f(s, y(s))-\lambda y(s)] d s\right. \\
& \left.\quad-\int_{0}^{T} G(t, s)[f(s, u(s))+\lambda u(s)-f(s, v(s))-\lambda v(s)] d s \mid\right\} \\
& \leq \sup _{t \in I} \int_{0}^{T} G(t, s) \mid f(s, x(s))+\lambda x(s)-f(s, u(s))-\lambda u(s) \\
& \quad+f(s, v(s))+\lambda v(s)-f(s, y(s))-\lambda y(s) \mid d s .
\end{aligned}
$$

Since the function $\varphi(x)$ is increasing and $(x, y) \leq(u, v)$, we have

$$
\varphi(x(s)-u(s)) \leq \varphi(d(x(s), u(s))), \quad \varphi(v(s)-y(s)) \leq \varphi(d(v(s), y(s))),
$$


we obtain the following:

$$
\begin{aligned}
d & (F(x(t), y(t)), F(u(t), v(t))) \\
& \leq \sup _{t \in I} \int_{0}^{T} G(t, s)|\lambda \varphi(x(s)-u(s))+\lambda \varphi(v(s)-y(s))| d s \\
& \leq \lambda \sup _{t \in I} \int_{0}^{T} G(t, s)|\varphi(d(x(s), u(s)))+\varphi(d(v(s), y(s)))| d s \\
& =\lambda(\varphi(d(x(s), u(s)))+\varphi(d(v(s), y(s)))) \cdot \sup \int_{t \in I}^{T} G(t, s) d s \\
& =\lambda(\varphi(d(x(s), u(s)))+\varphi(d(v(s), y(s)))) \cdot \sup \frac{1}{e^{\lambda T}-1}\left(\left[\frac{1}{\lambda} e^{\lambda(T+s-t)}\right]_{0}^{t}+\left[\frac{1}{\lambda} e^{\lambda(s-t)}\right]_{t}^{T}\right) \\
& =\lambda(\varphi(d(x(s), u(s)))+\varphi(d(v(s), y(s)))) \cdot \frac{1}{\lambda e^{\lambda T}-1}\left(e^{\lambda T}-1\right) \\
& =\varphi(d(x(s), u(s)))+\varphi(d(v(s), y(s))) \\
& <\frac{k}{2}[d(x(s), u(s))+d(v(s), y(s))] \\
& \leq \frac{k}{2} \sup \{|x(t)-u(t)|: t \in I\}+\frac{k}{2} \sup \{|v(t)-y(t)|: t \in I\} \\
& =\frac{k}{2}[d(x(t), u(t))+d(y(t), v(t))] .
\end{aligned}
$$

Then, by Proposition 1.3, $F$ is a generalized Meir-Keeler type contraction.

Finally, let $(\alpha(t), \beta(t)) \in C^{1}(I, \mathbb{R}) \times C^{1}(I, \mathbb{R})$ be a lower solution for the integral equation (3.14). Then we show that

$$
\alpha<F(\alpha, \beta), \quad \beta \geq F(\beta, \alpha) .
$$

Indeed, we have $\alpha^{\prime}(t)+\lambda \beta(t) \leq f(t, \alpha(t))-f(t, \beta(t))$ for any $t \in I$ and so

$$
\alpha^{\prime}(t)+\lambda \alpha(t) \leq f(t, \alpha(t))-f(t, \beta(t))+\lambda \alpha(t)-\lambda \beta(t)
$$

for any $t \in I$. Multiplying by $e^{\lambda t}$ in (3.31), we get the following:

$$
\left(\alpha(t) e^{\lambda t}\right)^{\prime} \leq[(f(t, \alpha(t))+\lambda \alpha(t))-(f(t, \beta(t))+\lambda \beta(t))] e^{\lambda t}
$$

for any $t \in I$, which implies that

$$
\alpha(t) e^{\lambda t} \leq \alpha(0)+\int_{0}^{t}[(f(s, \alpha(s))+\lambda \alpha(s))-f(s, \beta(s))-\lambda \beta(s)] e^{\lambda s} d s
$$


for any $t \in I$. This implies that

$$
\alpha(0) e^{\lambda t}<\alpha(T) e^{\lambda T} \leq \alpha(0)+\int_{0}^{T}[f(s, \alpha(s))+\lambda \alpha(s)-f(s, \beta(s))-\lambda \beta(s)] e^{\lambda s} d s
$$

and so

$$
\alpha(0)<\int_{0}^{T} \frac{e^{\lambda s}}{e^{\lambda T}-1}[f(s, \alpha(s))+\lambda \alpha(s)-f(s, \beta(s))-\lambda \beta(s)] d s
$$

Thus it follows from (3.35) and (3.33) that

$$
\begin{aligned}
\alpha(t) e^{\lambda t}< & \int_{t}^{T} \frac{e^{\lambda s}}{e^{\lambda T}-1}[f(s, \alpha(s))+\lambda \alpha(s)-f(s, \beta(s))-\lambda \beta(s)] d s \\
& +\int_{0}^{t} \frac{e^{\lambda(T+s)}}{e^{\lambda T}-1}[f(s, \alpha(s))+\lambda \alpha(s)-f(s, \beta(s))-\lambda \beta(s)] d s,
\end{aligned}
$$

and so

$$
\begin{aligned}
\alpha(t)< & \int_{0}^{t} \frac{e^{\lambda(T+s-t)}}{e^{\lambda T}-1}[f(s, \alpha(s))+\lambda \alpha(s)-f(s, \beta(s))-\lambda \beta(s)] d s \\
& +\int_{t}^{T} \frac{e^{\lambda(s-t)}}{e^{\lambda T}-1}[f(s, \alpha(s))+\lambda \alpha(s)-f(s, \beta(s))-\lambda \beta(s)] d s .
\end{aligned}
$$

Hence we have

$$
\alpha(t)<\int_{0}^{T} G(t, s)[f(s, \alpha(s))+\lambda \alpha(s)-f(s, \beta(s))-\lambda \beta(s)] d s=F(\alpha(t), \beta(t))
$$

for any $t \in I$.

Similarly, we have $\beta(t) \geq F(\beta(t), \alpha(t))$. Therefore, by Corollary 2.5, $F$ has a coupled fixed-point.

Example 3.9. In the integral equation (3.14), we put $\lambda=1.5, f(u, v)=u-v$ for all $(u, v) \in I \times \mathbb{R}$ and $T=0.5$. Then $f$ is a continuous function, and we have

$$
(x(t), y(t))=\left(\int_{0}^{0.5} G(t, s)[0.5 x(s)-0.5 y(s)] d s, \int_{0}^{0.5} G(t, s)[0.5 y(s)-0.5 x(s)] d s\right),
$$


where $x, y \in C(I, \mathbb{R})$, and

$$
G(t, s)= \begin{cases}\frac{e^{1.5(0.5+s-t)}}{e^{0.75}-1}, & \text { if } 0 \leq s<t \leq 0.5 \\ \frac{e^{1.5(s-t)}}{e^{0.75}-1}, & \text { if } 0 \leq t<s \leq 0.5\end{cases}
$$

Also, $(\alpha(t), \beta(t))=\left(-2 e^{-0.5 t}, 3 e^{-0.5 t}\right)$ is a lower solution of (3.39). Moreover, if we define $\varphi(x)=$ $x / 3$ for all $x \in[0, \infty)$, then $\varphi$ is increasing and, for any $x>0$, there exists $k=1 / 1.1 \in[0,1)$ such that $\varphi(x)=x / 3<(k / 2) x=x / 2$.2. For all $x, y \in \mathbb{R}$ with $y>x$, we have

$$
0<f(t, y)+\lambda y-[f(t, x)+\lambda x]=0.5(y-x) \leq \lambda \varphi(y-x)=1.5 \frac{y-x}{3}=0.5(y-x) .
$$

Therefore, all the conditions of Theorem 3.8 hold, and a solution of (3.39) exists.

\section{Acknowledgment}

This work was supported by the Basic Science Research Program through the National Research Foundation of Korea (NRF) funded by the Ministry of Education, Science and Technology (Grant no. 2011.0021821).

\section{References}

[1] S. Banach, "Sur les operations dans les ensembles abstraits et leur application aux equations integrales," Fundamenta Mathematicae, vol. 3, pp. 133-181, 1922.

[2] R. P. Agarwal, M. Meehan, and D. O'Regan, Fixed Point Theory and Applications, Cambridge University Press, 2001.

[3] R. P. Agarwal, M. A. El-Gebeily, and D. O’Regan, “Generalized contractions in partially ordered metric spaces," Applicable Analysis, vol. 87, no. 1, pp. 109-116, 2008.

[4] D. W. Boyd and J. S. W. Wong, "On nonlinear contractions," Proceedings of the American Mathematical Society, vol. 20, pp. 458-464, 1969.

[5] A. Branciari, "A fixed point theorem for mappings satisfying a general contractive condition of integral type," International Journal of Mathematics and Mathematical Sciences, vol. 29, no. 9, pp. 531$536,2002$.

[6] L. B. Cirić, "A generalization of Banach's contraction principle," Proceedings of the American Mathematical Society, vol. 45, pp. 267-273, 1974.

[7] J. Dugundji and A. Granas, Fixed Point Theory, Springer, New York, NY, USA, 2003.

[8] D. J. Guo and V. Lakshmikantham, Nonlinear Problems in Abstract Cones, Academic Press, Boston, Mass, USA, 1988.

[9] A. Meir and E. Keeler, "A theorem on contraction mappings," Journal of Mathematical Analysis and Applications, vol. 28, pp. 326-329, 1969.

[10] J. J. Nieto and R. Rodríguez-López, "Contractive mapping theorems in partially ordered sets and applications to ordinary differential equations," Order, vol. 22, no. 3, pp. 223-239, 2005.

[11] B. E. Rhoades, "A comparison of various definitions of contractive mappings," Transactions of the American Mathematical Society, vol. 226, pp. 257-290, 1977.

[12] D. R. Smart, Fixed Point Theorems, Cambridge University Press, London, UK, 1974.

[13] T. Suzuki, "Meir-Keeler contractions of integral type are still Meir-Keeler contractions," International Journal of Mathematics and Mathematical Sciences, Article ID 39281, 6 pages, 2007. 
[14] T. Suzuki, "A generalized Banach contraction principle that characterizes metric completeness," Proceedings of the American Mathematical Society, vol. 136, no. 5, pp. 1861-1869, 2008.

[15] E. Zeidler, Nonlinear Functional Analysis and Its Applications I: Fixed-Point Theorems, Springer, Berlin, Germany, 1986.

[16] T. Gnana Bhaskar and V. Lakshmikantham, "Fixed point theorems in partially ordered metric spaces and applications," Nonlinear Analysis, vol. 65, no. 7, pp. 1379-1393, 2006.

[17] V. Lakshmikantham and L. Cirić, "Coupled fixed point theorems for nonlinear contractions in partially ordered metric spaces," Nonlinear Analysis, vol. 70, no. 12, pp. 4341-4349, 2009.

[18] M. Abbas, Y. J. Cho, and T. Nazir, "Common fixed point theorems for four mappings in TVS-valued cone metric spaces," Journal of Mathematical Inequalities, vol. 5, no. 2, pp. 287-299, 2011.

[19] Y. J. Cho, G. He, and N.-J. Huang, "The existence results of coupled quasi-solutions for a class of operator equations," Bulletin of the Korean Mathematical Society, vol. 47, no. 3, pp. 455-465, 2010.

[20] Y. J. Cho, R. Saadati, and S. Wang, "Common fixed point theorems on generalized distance in ordered cone metric spaces," Computers E Mathematics with Applications, vol. 61, no. 4, pp. 1254-1260, 2011.

[21] Y. J. Cho, M. H. Shah, and N. Hussain, "Coupled fixed points of weakly F-contractive mappings in topological spaces," Applied Mathematics Letters, vol. 24, no. 7, pp. 1185-1190, 2011.

[22] M. E. Gordji, Y. J. Cho, and H. Baghani, "Coupled fixed point theorems for contractions in intuitionistic fuzzy normed spaces," Mathematical and Computer Modelling, vol. 54, pp. 1897-1906, 2011.

[23] E. Graily, S. M. Vaezpour, R. Saadati, and Y. J. Cho, "Generalization of fixed point theorems in ordered metric spaces concerning generalized distance," Fixed Point Theory and Applications, vol. 2011, article 30, 2011.

[24] W. Sintunavarat, Y. J. Cho, and P. Kumam, "Common fixed point theorems for $c$ in ordered cone metric spaces," Computers \& Mathematics with Applications, vol. 62, pp. 1969-1978, 2011.

[25] W. Sintunavarat, Y. J. Cho, and P. Kumam, "Coupled coincidence point theorems for contractions without commutative condition in intuitionistic fuzzy normed spaces," Fixed Point Theory and Applications, vol. 2011, article 81, 2011.

[26] B. Samet, "Coupled fixed point theorems for a generalized Meir-Keeler contraction in partially ordered metric spaces," Nonlinear Analysis, vol. 72, no. 12, pp. 4508-4517, 2010. 


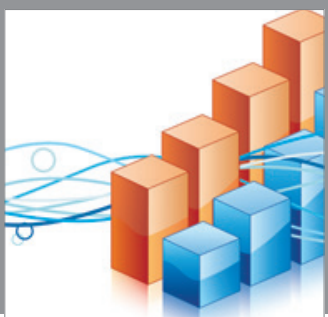

Advances in

Operations Research

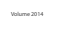

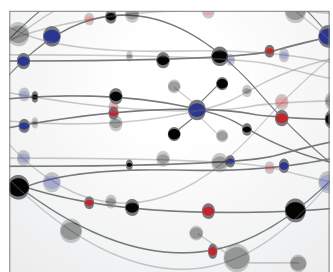

\section{The Scientific} World Journal
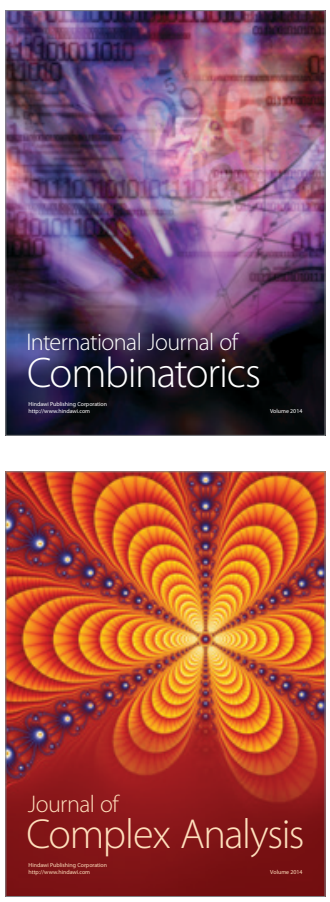

International Journal of

Mathematics and

Mathematical

Sciences
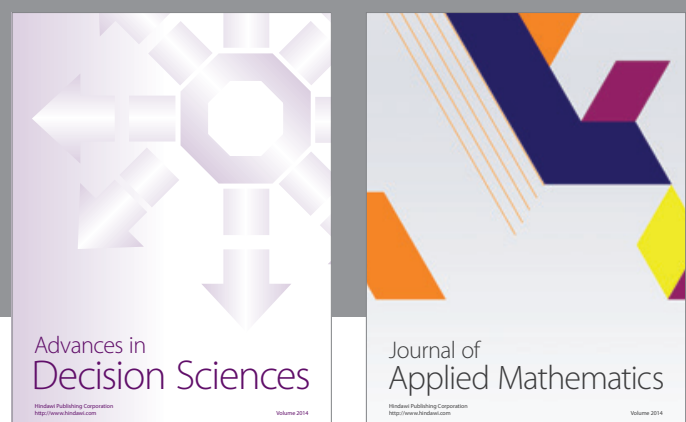

Journal of

Applied Mathematics
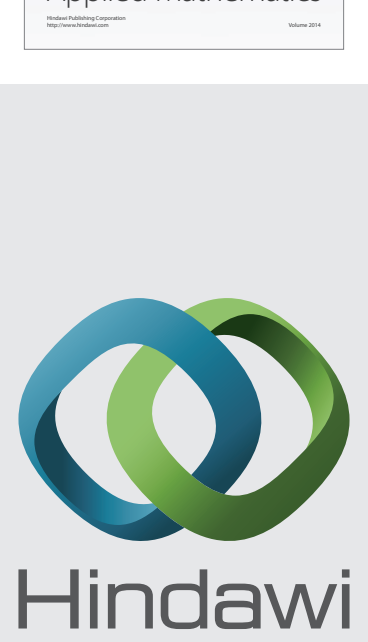

Submit your manuscripts at http://www.hindawi.com
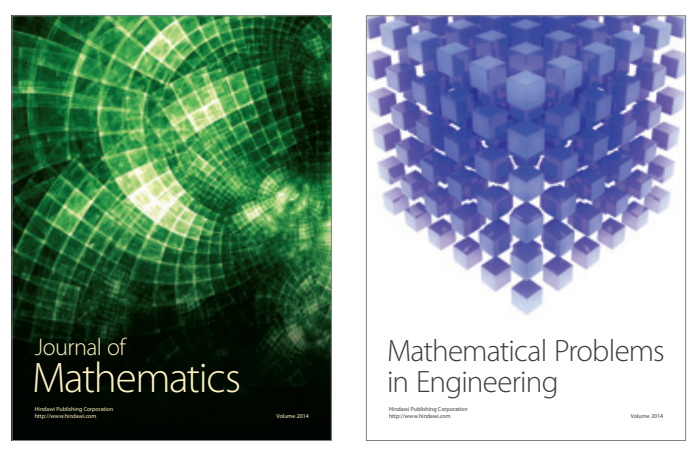

Mathematical Problems in Engineering
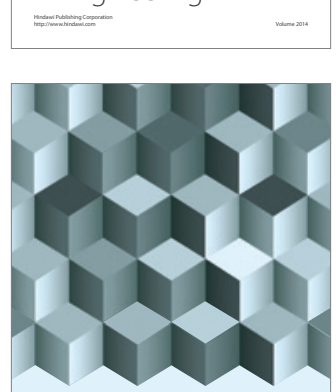

Journal of

Function Spaces
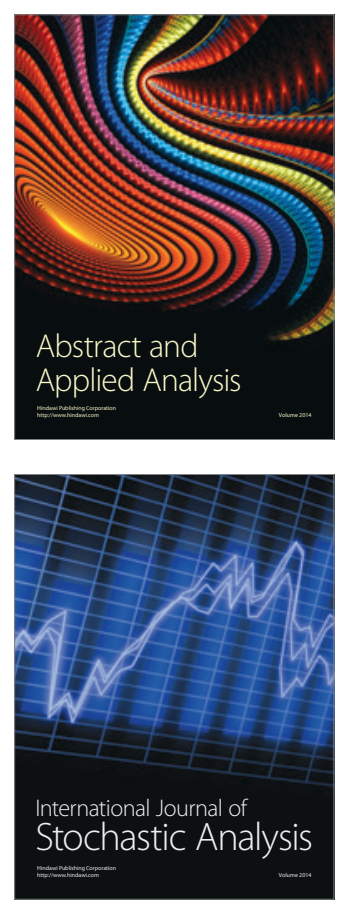

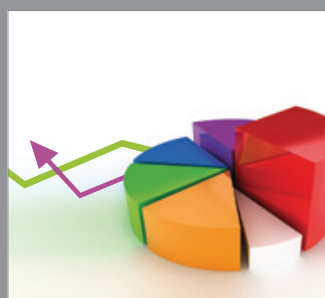

ournal of

Probability and Statistics

Promensencen
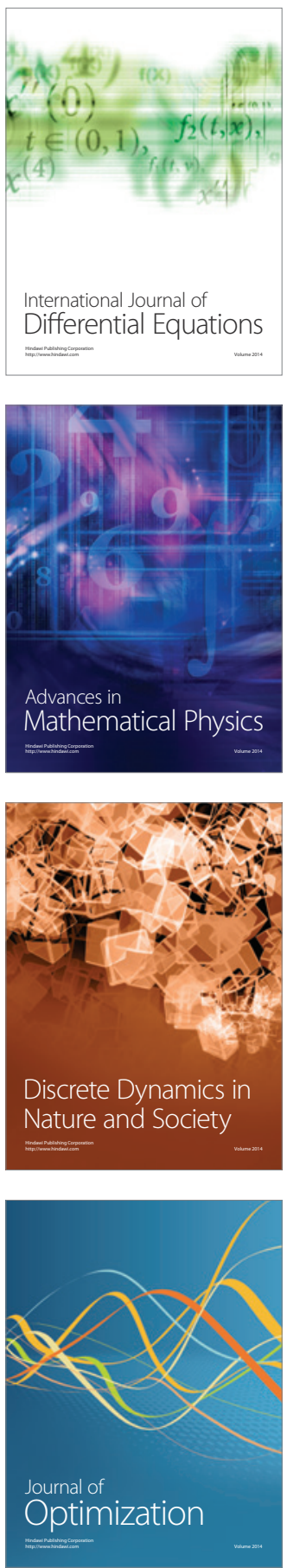